\title{
Energy and Exergy Analysis of Organic Rankine Cycle Using Alternative Working Fluids
}

\author{
Deepak Tiwari ${ }^{1}$, Akhilesh Arora ${ }^{2}$, Naushad Ahmad Ansari ${ }^{3}$, ${ }^{*}$ Dr.A.F.Sherwani
}

\begin{abstract}
The present study is based on parametric investigation in terms of thermal efficiency, exergetic efficiency and exergy destruction with the help mathematical modeling on different ORC models using different fluids. The Thermal efficiency of ORC model of Saturated, Trilateral is compared by using working fluids such as (HFO-1234yf,HFC-134a,HFC-245fa,Ethanol,Iso-pentane by varying expander inlet temperature (30$\left.160^{\circ} \mathrm{C}\right)$, at fixed condensation temperature $\left(30^{\circ} \mathrm{C}\right)$ assuming fixed expander isentropic efficiency $(=0.75)$ and fixed isentropic pump efficiency $(=0.60)$. The Thermal efficiency as well as exergetic efficiency has been observed best for theHFO-1234yf and found nearly close with HFC-134a. HFO-1234yf has good potential for working fluid for ORC application for low to medium temperature. It has zero global warming potential (GWP), zero Ozone layer depletion (ODP) and very Low evaporation Temperature. This paper provides a basis to compare the thermal and exergetic efficiency for various working fluids and exergy destruction in various component such as Expander, Evaporator,Condenser,Pump for saturated and Trilateral cycle when used with $R$-1234yf as working substance.
\end{abstract}

Keywords: Organic Rankine cycle models, Energy analysis \& Exergy analysis, Exergy destruction; R-1234yf, $R-134 a, R-245 f a$, Ethanol, Isopentane.

Biographical notes: Deepak Tiwari is pursuing Ph.D. From Department of Mechanical Engineering of Jamia Millia Islamia University, Delhi. His research area includes exergy analysis of thermal systems and alternative refrigerants.

Akhilesh Arora is working as an Associate Professor in the Department of Mechanical Engineering and Automation at Indira Gandhi Delhi Technological University for Women, Delhi, India. He obtained his PhD from the Indian Institute of Technology, Delhi in 2011. His research area includes alternate refrigerants, alternate refrigeration technologies and exergy analysis of thermal systems.

Naushad Ahmad Ansari is working as an Assistant Professor in Department of Mechanical Engineering at Delhi Technological University, Delhi. He obtained his Master of Technology (M. Tech) in Thermal Engineering from Aligarh Muslim University, Aligarh in 2000. His research area includes alternate refrigeration technologies, exergy analysis of thermal systems, fluid mechanics and computational fluid dynamics.

Dr. A.F.Sherwani is working as an Assistant Professor in Department of Mechanical Engineering of Jamia Millia Islamia University, Delhi. His research area includes alternate refrigeration technologies, exergy analysis of thermal systems and renewable, sustainable energy and life cycle analysis.

\section{Introduction}

Heat is recovered by organic Rankine cycles (ORC).Low grade heat is useful for operation of Organic Rankine cycle the Low grade heat is available from various heat sources such as solar ,ocean , thermal, geothermal, biomass, and available source of heat from engine exhaust or industrial process waste heat. The word ORC has been used from the fact that it is basically a Rankine cycle which runs organic Fluid as a working substance Serrano et al. [1] did the theoretical investigation and has suggested that possibility to introduce the concept of recovery of waste heat in heavy duty diesel engine of two stage turbocharged engine and introduced the best use of IC engine Exhaust waste heat coupling with simple water Rankine cycle. Wang.et al. [2] Proposed and designed a experimental set up of solar operated rankine cycle by using R-245fa as a working substance and used evacuated and Flat plate collector and found the efficiency of overall power generation of evacuated collector is $4.2 \%$ and with flat plate collector is 3.2\%. DiGenova et al. [3] proposed a customized organic Rankine cycle based on the heat source from Fischer Tropsch plant reactor and found that the steam Rankine cycle may achieve $20.6 \%$ conversion efficiency using this heat source and by using hexane as a working substance in ORC the conversion efficiency may reach 20.6\%. Wang et al. [4] proposed the concept of discontinuous waste heat recovery at low temperature and did the performance analysis with the effect of temperature at exit to the heat source on thermal efficiency, power consumption ,mass flow rate,expander outlet temperature, net power output,cycle irreversibility,exergy efficiency by using various working substances such as acetone,butane,isopentane,pentane,R-245fa,CF31,R-414b,R-21 and found acetone shows the least exergy destruction and R-245fa shows maximum thermal efficiency at fixed pinch point temperature difference. Larjola [5] suggested the applicability of high speed (ORC) and found that the low temperature waste heat 
sources are such as combustion of I.C. engine blast furnace hot gases steel industries diesel engine exhaust gases, gas turbine can be converted into electricity with highest efficiency. Li et al. [6] Analyzed the effect of fouling in organic rankine cycle and concluded that convective and radiative heat losses increase with increase in operating temperature. Quoilin et al. [7] proposed the design optimization and performance of economical solar operated (ORC) to generate power for rural and remote area and found that overall efficiency of electricity can be reached 7to $8 \%$. Heberle et al. [8] carried out the exergy analysis of a combined heat and power generating ORC using geo-thermal energy inlet source $\left(>450^{\circ} \mathrm{k}\right)$ and used four working fluids are such as isobutene,isopentane,R-227ea,R-245fa and found that R-227 shows highest second law efficiency for inlet temperature 353-423k and isobutene is best working fluid for higher temperature inlet source of geothermal water . Aleksandra\& Borsukiewicz [9] has calculated pump work in ORC by using 18 working substance

in subcritical organic rankine cycle plant and found that for lower critical temperature of the working substance and the pressure in the cycle will be more thus pumping power will be more.

Nobru et al. [10] presented Study on First Law efficiency(Energy analysis) by using HFO-1234yf as working substance for low to medium temperature range of Organic Rankine cycle and found that it is potential working substance having negligible ozone depletion potential, global warming potential and found highest thermal efficiency $8.8-11.4 \%$ for expander inlet temperature range of $\left(180-160^{\circ} \mathrm{C}\right)$ in SupercriticalOrganic Rankine cycle.Till now there is no study about exergy analysis and exergy destruction in various component expander,pump,condenser,and evaporator using HFO-1234yf as working substance in Organic Rankine cycle(ORC)

In this paper, the first and second law analysis of ORC have been carried out using working fluids as HFO-1234yf,HFC-134a,HFC-245fa,Ethanol,Iso-pentane.

\section{Basic Organic Rankine Cycle}

Fig.1. Shows schematic diagram of Organic Rankine cycle,It consist of following component are such as Evaporator,Expander, Condenser, Pump.

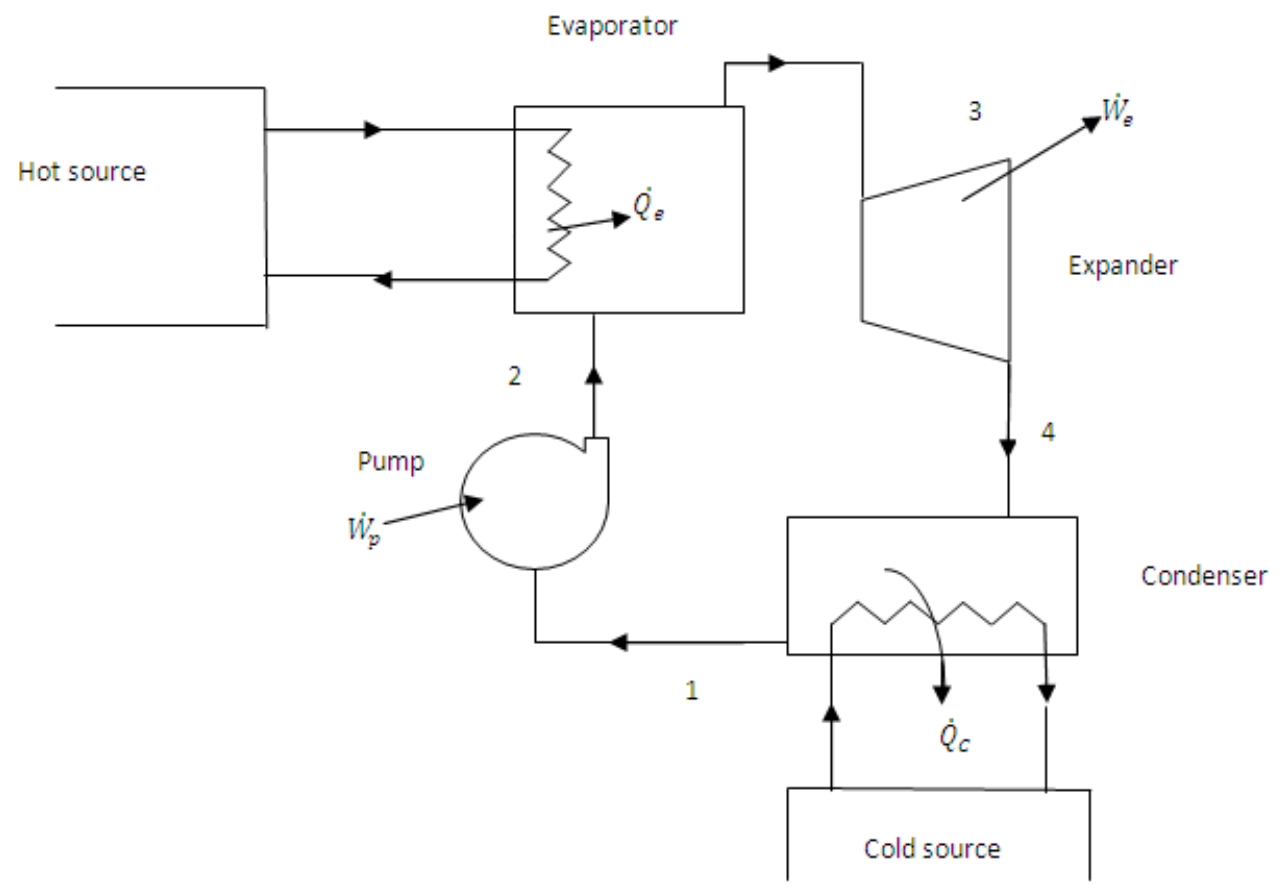

\subsection{Working Fluids}

There are five working fluids used in this simulation study: HFO-1234yf, HFC-134a, HFC-245fa, isopentane, and ethanol. The working substances HFC-245fa and iso-pentane are dry fluid used to utilize lowtemperature heat source from industrial power plants waste.Ethanol and HFC-134a are wet fluids and Ethanol is in use now a days as a good automotive working fluid in organic rankine cycle because of it's' capability to perform best for medium-temperature range $\left(200-300^{\circ} \mathrm{C}\right)$. The purpose of using organic substance as working fluids is because they have evaporation temperature which is found to be very low as compared to steam (water vapor) and has this tendency to change into vapor or superheated vapor by using low to medium-temperature heat source.The organic substances dry (HFC-245fa, Iso-pentane) and isentropic (HFC-1234yf) which may enhance the expander life more; The vapor gets expansion in the expander has tendency to remain in dry or either saturated or superheated vapor conditions. 


\begin{tabular}{|l|l|l|l|l|l|l|l|l|}
\hline $\begin{array}{l}\text { Working } \\
\text { fluid }\end{array}$ & $\begin{array}{l}\text { Flammability/ } \\
\text { Toxicity }\end{array}$ & Type & $\begin{array}{l}\text { Molecular } \\
\text { mass(kg/kmol })\end{array}$ & $T_{c r i}\left({ }^{0} C\right)$ & $T_{b p}\left({ }^{0} C\right)$ & $P_{c r i}(M P a)$ & ODP & $\begin{array}{l}\text { GWP(10 } \\
0 y r)\end{array}$ \\
\hline HFO-1234yf & No & Isentropic & $114.042^{\mathrm{a}}$ & $94.7^{\mathrm{a}}$ & $-29.45^{b}$ & $3.382^{\mathrm{b}}$ & $\sim 0$ & 4 \\
\hline HFC-134a & No & Wet & $102.03^{\mathrm{b}}$ & $101^{\mathrm{a}}$ & $-26.0745^{b}$ & $4.0593^{\mathrm{b}}$ & $\sim 0$ & $1320^{\mathrm{c}}$ \\
\hline HFC-245fa & No & Dry & $134.05^{\mathrm{b}}$ & $154^{\mathrm{a}}$ & $15.14^{b}$ & $3.651^{\mathrm{b}}$ & $\sim 0$ & $1020^{\mathrm{c}}$ \\
\hline Isopentane & Yes & Dry & $72.149^{\mathrm{b}}$ & $187.2^{\mathrm{a}}$ & $27.83^{b}$ & $3.387^{\mathrm{b}}$ & $\sim 0$ & $\sim 20^{\mathrm{c}}$ \\
\hline Ethanol & Yes & Wet & $46.068^{\mathrm{b}}$ & $240.7^{\mathrm{a}}$ & $78.24^{b}$ & $6.148^{\mathrm{b}}$ & na & Na \\
\hline Acetone & No & Wet & 58.08 & $3.60^{\mathrm{a}}$ & 329.15 & $4.70^{\mathrm{a}}$ & $\sim 0$ & Na \\
\hline
\end{tabular}

Table-1Comparative characterstic of working fluids (HFO-1234yf, HFC-134a, HFC-245fa, Isopentane,

a. a Ref.Akasa et al

Ethanol, Acetone)

b. b REFPRP:Ref.Lemmon et al.[20]

c. c Ref.calm et al [21]

\subsection{Saturated cycle model:}

Fig.2 shows T-s diagram for wet fluids (such as HFC-134a,Ethanol)It is similar to trilateral cycle it is very compact design system can be used to obtain reasonable thermal efficiencies by recovering waste heat from low temperature level. The temperature-entropy (T-S) diagram for the saturated cycle is shown by the cycle path 1-2-3-4-1. The heat is supplied to evaporator (2-3) at isobaric condition. The process (1-2) is reversible adiabatic pumping the process (3-4) is reversible adiabatic expansion. The process (4-1) shows constant pressure heat rejection process

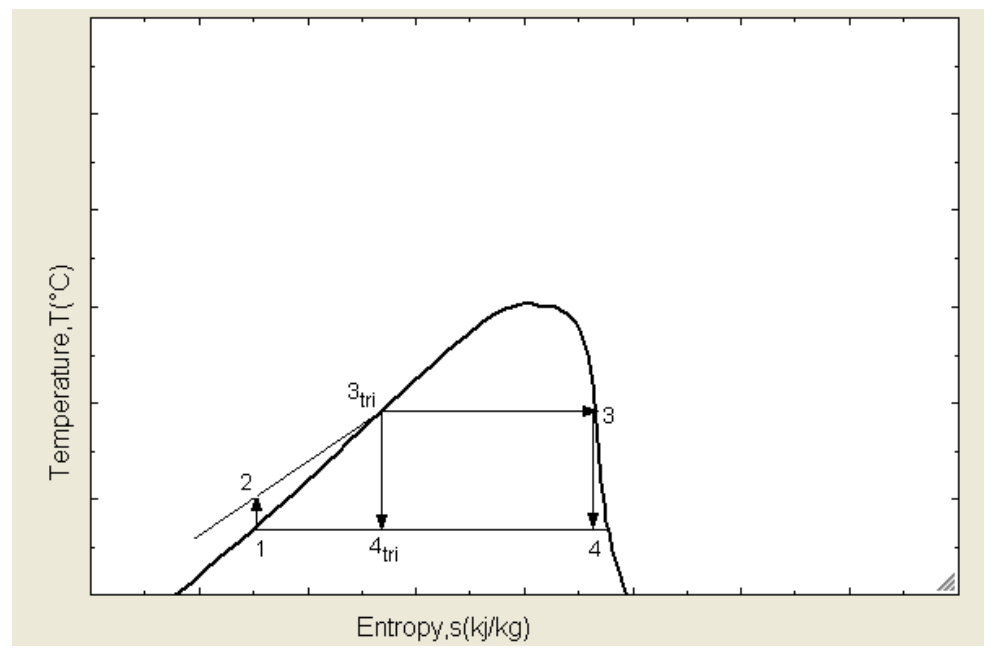

\subsection{Trilateral cycle model:}

Fig.3 Shows T-s diagram of ORC for isentropic fluid (HFO-1234yf) The trilateral organic rankine cycle seems to be triangular rankine cycle. It looks very simple cycle when compared with a conventional cycle, it shows very competitive performance when it is used for low temperature source of heat. It has low operating cost of same sized components.

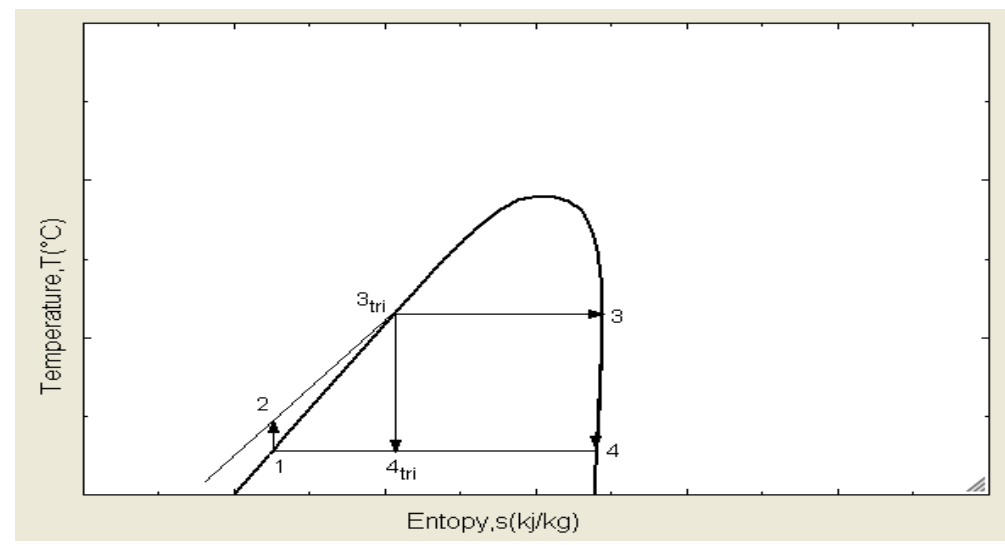


Fig 4 Shows T-s diagram of ORC for dry fluid (HFC-245fa,Isopentane)

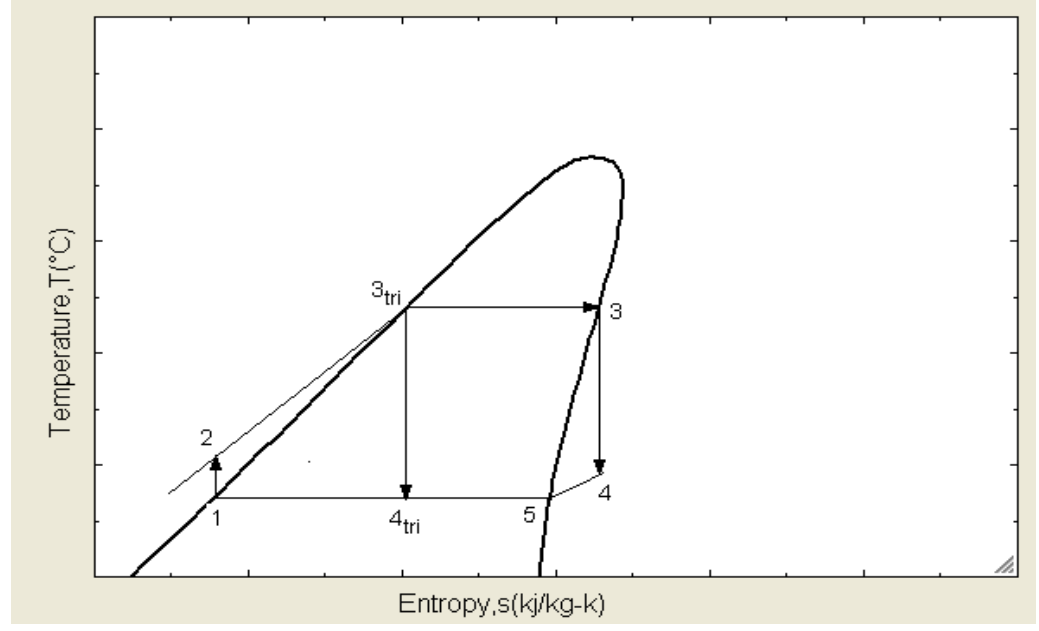

The reason of using this cycle is that the temperature profile of working substance is matching perfectly to the heat source. Its' operating pressure is optimum, so it is used economically for where low powered heat application is required.

In this simulation work, T-s diagram for the trilateral ORC model is represented by cycle path 1-2-3-41. The pressure, at which pump is working which is same as evaporation pressure but practically it is lower than the critical pressure of the working fluid. The inlet temperature to the expander is maintained at saturated condition.

The cycle consists of reversible adiabatic (isentropic) pumping shown by state (1-2) of a working fluid then, followed by constant pressure heat supply to the working fluid (2-3),then isentropic expansion of the working fluid containing two-phase mixture at state (3-4) is then entered, for constant pressure heat rejection in condenser and finally return with two-phase mixture at saturated liquid state (4-1).The trilateral cycle is differed by conventional cycle where the working substance remains in the form of liquid when it exit from the evaporator. By keeping constant condenser temperature, the thermal efficiency substantially increases when operating inlet temperature varies from $\operatorname{Tin}=50^{\circ} \mathrm{C}$ to $170 \pm 10^{\circ} \mathrm{C}$ then falls slowly when the expander inlet temperature further reaches up to $200^{\circ} \mathrm{C}$.

\subsection{Energy Analysis}

The following assumption are made during thermodynamic analysis of ORC

1) The process is steady -flow and steady state;2)There is no pressure drop in connecting pipes and heat exchanger:3)process in expander and pump is isentropic;4)There is no heat loss from equipments and pipes;5)The heat carrier of exhaust gas is non- corrosive and non-condensable in heat exchange process ;6)The isentropic expander efficiency $75 \%$.) ;7)The isentropic pump efficiency is $60 \%$. The fixed condensation temperature is $30^{\circ} \mathrm{C}$.

The general energy balance equation for all existing cycle (Saturated, Trilateral, Supercritical, Superheated, and Subcritical) is as follow:

The isentropic pump efficiency \&power

$$
\begin{aligned}
& \eta_{p}=\frac{h_{2 s}-h_{2}}{h_{2}-h_{1}} \\
& W_{P}=\dot{m} *\left(h_{2}-h_{1}\right)
\end{aligned}
$$

For the expander

Isentropic efficiency

$$
\begin{aligned}
& \eta_{e}=\frac{\left(h_{3}-h_{4}\right)}{\left(h_{3}-h_{4 s}\right)} \\
& W_{e}=\dot{m} *\left(h_{3-} h_{4}\right)
\end{aligned}
$$

The amount of heat supplied to the working fluid into evaporator

$$
Q_{\text {in }}=\dot{m} *\left(h_{3}-h_{2}\right)
$$




\section{Thermal Efficiency Of the ORC cycle}

$$
\begin{gathered}
\eta_{t h}=\frac{w_{e}-W_{P}}{Q_{i n}} \\
\eta_{t h}=\frac{\left(h_{3}-h_{4}\right)-\left(h_{2}-h_{1}\right)}{Q_{\text {in }}}
\end{gathered}
$$

\subsection{Exergy Analysis}

The second law of thermodynamics assists in evaluating the performance of the system based on exergy, which always decreases owing to irreversibility. Exergy is the measure of usefulness, quality or potential of a stream to cause change and an effective measure of the potential of a substance to impact the environment (Dincer, 2003). Exergy balance for a control volume undergoing steady state process is expressed as (Lee and Sherif, 2001).

$$
\dot{E} D_{i}=\sum(\dot{m} e)_{\text {in }}-\sum(\dot{m} e)_{\text {out }}+\left[\sum\left(\dot{Q}\left(1-\frac{T_{O}}{T}\right)\right)_{\text {in }}+\sum\left(\dot{Q}\left(1-\frac{T_{O}}{T}\right)\right)_{\text {out }}\right] \pm \sum \dot{W}
$$

Where EDi represents the rate of exergy destruction occurring in the process in the component under consideration

The first two terms on the right hand side represent exergy of streams entering and leaving the control volume. The third and fourth terms are the exergy associated with heat transfer $\mathrm{Q}$ from the source maintained at constant temperature $\mathrm{T}$ and is equal to work obtained by Carnot engine operating between $\mathrm{T}$ and $\mathrm{T} 0$. The last term is the mechanical work transfer to or from the control volume. Second law performance of the system can be measured in terms of exergetic efficiency.Exergetic efficiency can also be expressed in terms of total exergy destruction and exergy supplied to the system.

\section{Exergy destruction in evaporator:}

$$
E_{\text {devap }}=\left(h_{2}-T_{O} * S_{2}\right)-\left(h_{3}-T_{0} * S_{3}\right)+q_{s} *\left[1-T_{O} /\left(T_{3}+273\right)\right]
$$

\section{Exergy destruction in expander:}

$$
E_{\text {dexp }}=\left(h_{3}-T_{O} * S_{3}\right)-\left(h_{4}-T_{O} * S_{4}\right)-\left(h_{3}-h_{4}\right)
$$

Exergy destruction in condenser:

$$
\left(h_{4}-T_{O} * S_{4}\right)-\left(h_{1}-T_{o} * S_{1}\right)
$$

Exergy destruction in pump:

$$
\begin{aligned}
& E_{\text {dpump }}=\left(h_{1}-T_{o} * S_{1}\right)-\left(h_{2}-T_{o} * S_{2}\right)+\left(h_{2}-h_{1}\right) \\
& E_{\text {dtotal }}=E_{\text {devap }}+E_{\text {dexp }}+E_{\text {dcond }}+E_{\text {dpump }}
\end{aligned}
$$

\section{Exergetic Efficiency}

$$
\begin{aligned}
& \eta_{\text {ex }}=1-E_{\text {dtotal }} / E_{\text {inpu }} \\
& E_{\text {input }}=q_{S} *\left[1-T_{O} /\left(T_{3}+273\right)\right]+W \\
& \eta_{\text {ex } 1}=W_{T} / E_{\text {input }}
\end{aligned}
$$

\section{Result And Discussion}

This section deals with the result and discussion for simple ORC cycle with various working fluids at different Expander inlet temperature at fixed condenser temperature $\left(30^{\circ} \mathrm{C}\right)$, Isentropic Expander efficiency $\left(\eta_{T}=75 \%\right)$, IsentropicpumpEfficiency $\left(\eta_{P}=60 \%\right)$.

Fig.5. Shows relative Comparison of Thermal Efficiency of Saturated by using various working fluid. In saturated Rankine cycle model by using HFO-1234yf shows Lowest Thermal Efficiency (7\%) and ethanol shows highest thermal efficiency $(20 \%)$ as compared to other working fluid in temperature Range $\left(30-90^{\circ} \mathrm{C}\right)$. 


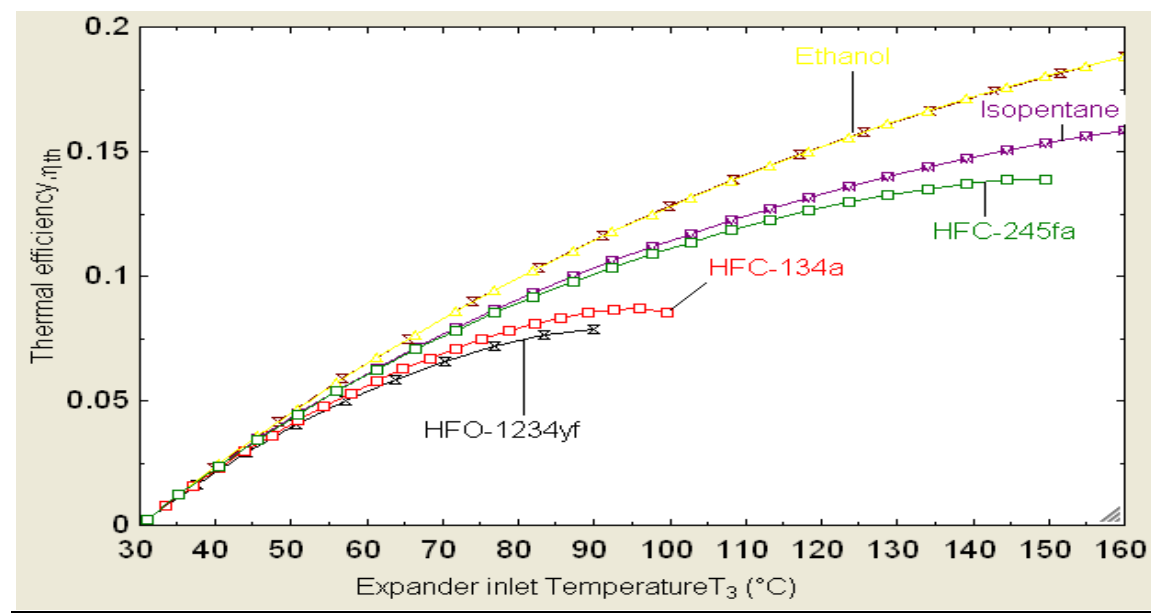

\section{Exergetic Efficiency Comparison of various Working Fluid in Saturated Cycle.}

Fig.6.Exergetic efficiency for saturated ORC HFO-1234yf shows lower exergetic efficiency (52\%) Ethanol shows higher Exegetic efficiency $(60 \%)$ for expander inlet temperature $\left(30-100^{\circ} \mathrm{C}\right)$.

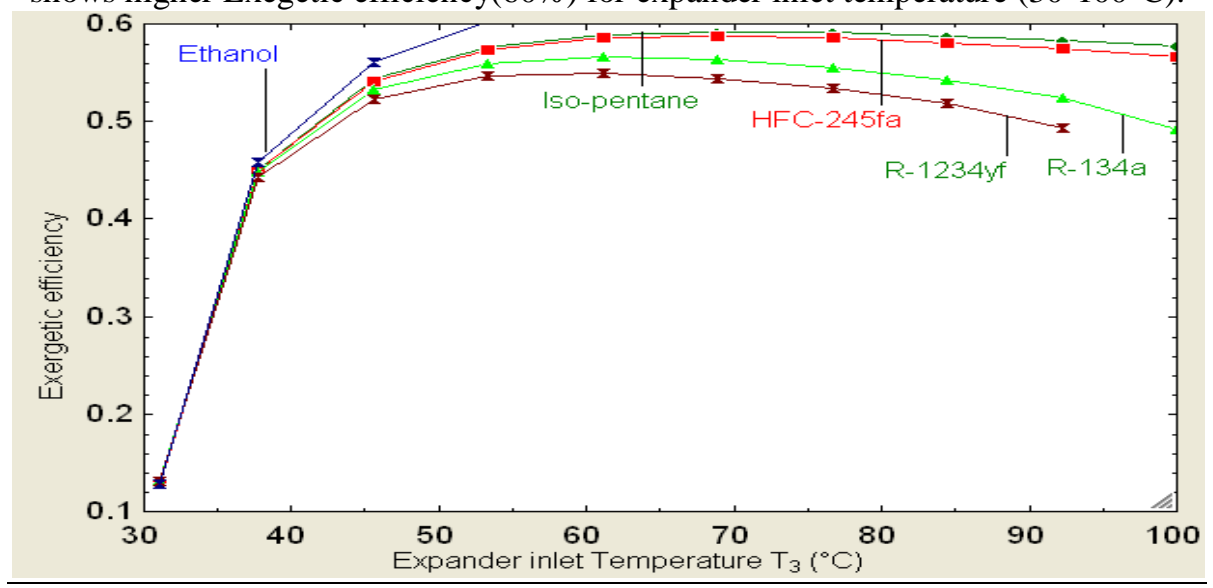

Fig.7. shows Comparison of Exergy Destruction in variour component (Expander, Evaporator, Pump, and Condenser) in Saturated cycle using R-1234yf

The exergy destruction ( $7 \mathrm{kw}$ ) in evaporator is highest as compare to expander, pump, condense and pump shows the lowest exergy destruction $(2 \mathrm{kw})$ for temperature range of $\left(30-100^{\circ} \mathrm{C}\right)$.

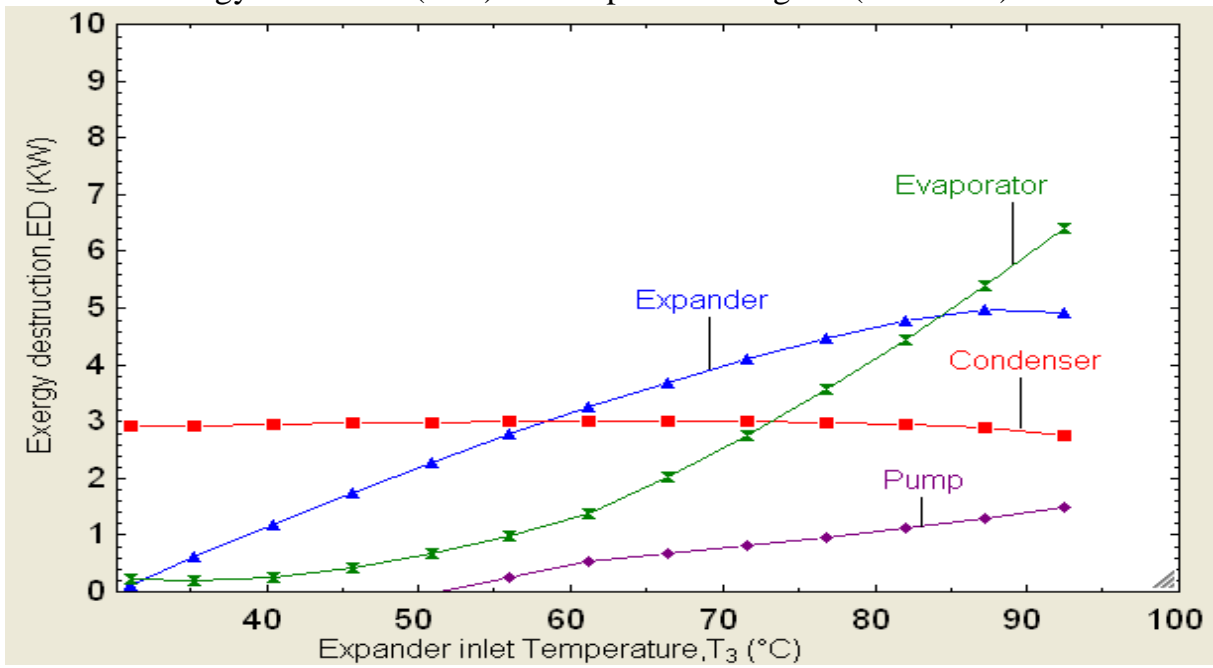


Fig.8. Shows relative Comparison of Thermal Efficiency with Expander inlet Temperature of Trilateral cycle by using various workingFluid .

It has been observed that Ethanol shows higher thermal efficiency (14\%), HFO-1234yf lower thermal efficiency $(5 \%)$ for expander inlet temperate $\left(30-160^{\circ} \mathrm{C}\right)$.

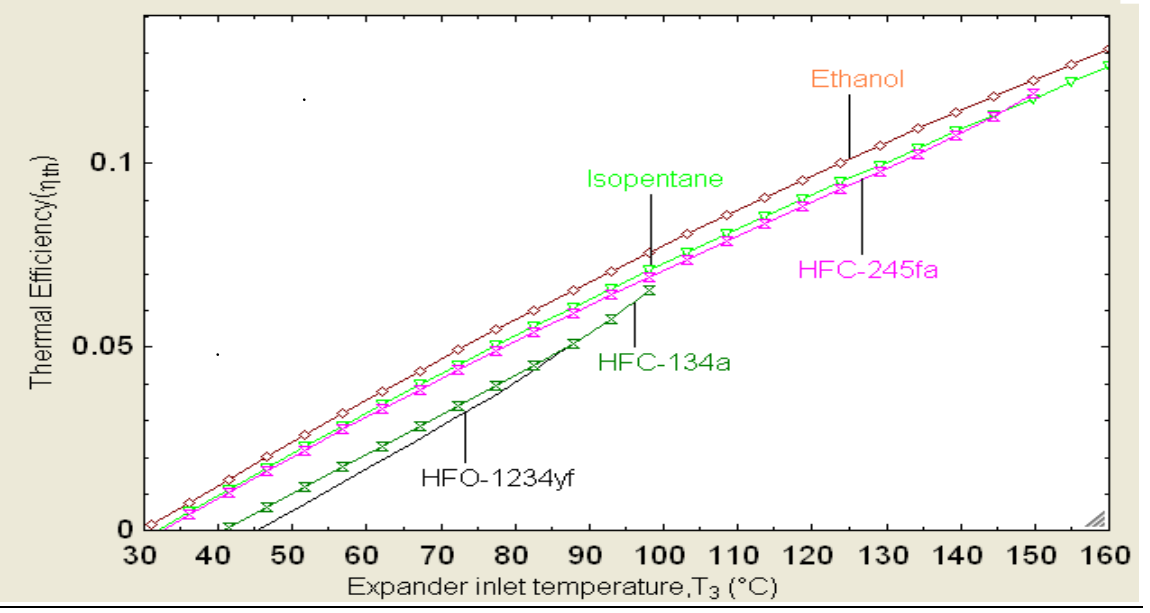

Fig.9 Shows. Exergetic Efficiency Comparison of various Working Fluid in Trilateral cycle HFC-134a shows highest exergetic efficiency(42\%) is close to the exergetic efficiency(40\%) when HFO$1234 y f$ is used.

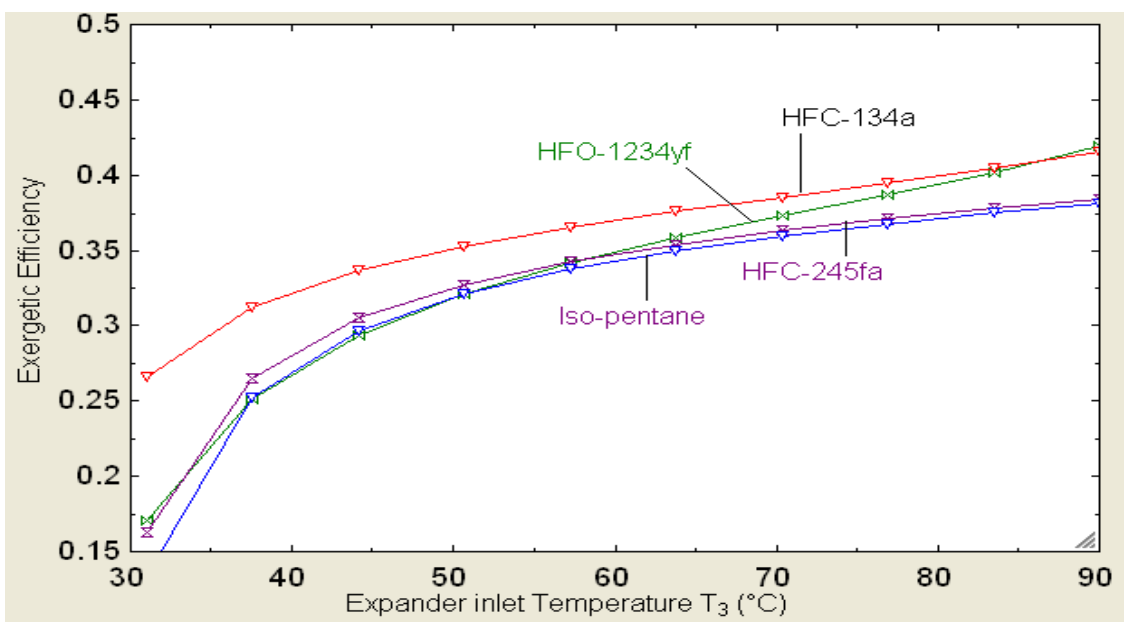

Fig.10. Shows relative Comparison of Exergy destruction of Trilateral cycle by using HFO-1234yf as working Fluid.

The exergy destruction in evaporator $(1.8 \mathrm{kw})$ is highest as compare to expander, pump, condenser and pump shows $(0.6 \mathrm{kw})$ the lower exergy destruction.

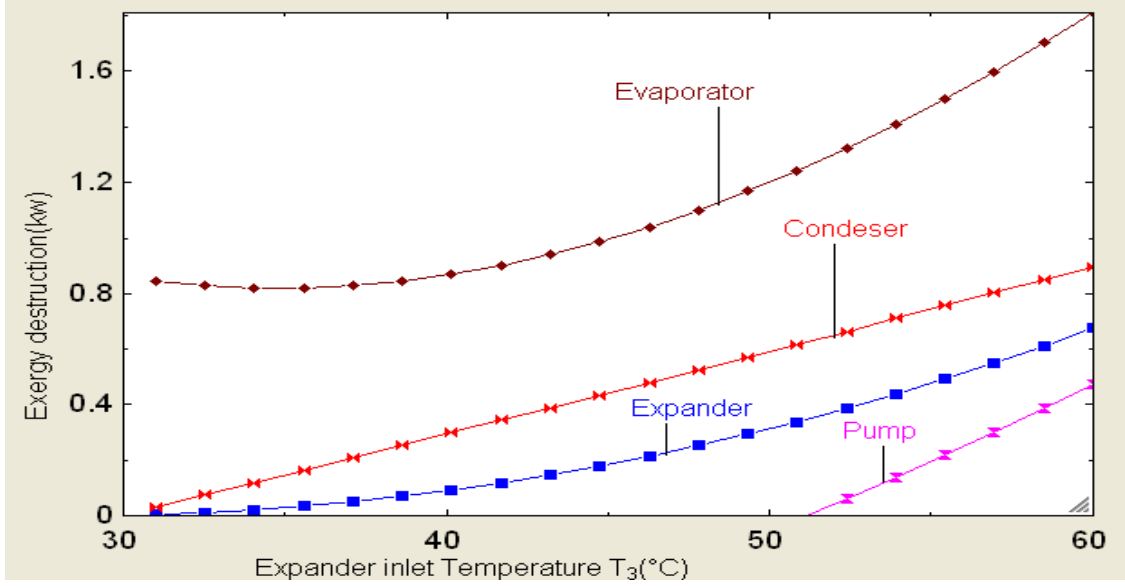




\section{Conclusions}

The first law efficiency obtained in this section is similar to the result obtained by Nobru et.al. On the basis of result obtained from the thermodynamic model, the following conclusions are drawn:-HFO-1234yf is used as working fluid in two ORC models through first order simulation are Saturated, Trilateral cycle. The first law efficiency of HFO-1234yf has been compared with that of other working fluids (R-245fa, R-134a, Isopentane, and Ethanol). HFO-1234yf may be used for low-to medium-temperature ORC applications; Thermal efficiency is not always the best among the other simulated fluids depending on the temperature level of expander. So, the HFO-1234yf can be used as a good alternative working fluid for low to medium-temperature heat sources of ORC applications (at prescribed expander inlet temperature of up to $170^{\circ} \mathrm{C}$ ) if ODP and GWP are considered within safe limit. Beyond the above work, in this paper the Exergetic efficiency and exergy destruction has been calculated and compared by using HFO-1234yf as working fluid with other working fluids(R-245fa, R- 134a,Isopentane, and Ethanol) which are as follows.

1) The exergetic efficiency of Ethanol is highest in saturated cycle (60\%) when expander inlet temperature is from $30^{\circ} \mathrm{C}-100^{\circ} \mathrm{C}$.

2) The exergetic efficiency of R-1234yf (9\%) is found very close to exergetic efficiency of R-134a(10\%) in saturated cycle.

3) The exergetic efficiency of $\mathrm{R}-134 \mathrm{a}(42 \%)$ when used in Trilateral cycle is close to the exergetic efficiency $(40 \%)$ of R-1234yf as a working substance for expander inlet Temperature from $30^{\circ} \mathrm{C}-90^{\circ} \mathrm{C}$.

4) The exergy destruction in evaporator is highest (7kw) and Lowest in pump (2kw) when R-1234yf is used as working substance in saturated cycle for expander inlet temperature from $0{ }^{\circ} \mathrm{C}-100^{\circ} \mathrm{C}$.

5) The exergy destruction is highest $(1.8 \mathrm{kw})$ in evaporator and lowest in pump $(0.18 \mathrm{kw})$ for expander inlet temperature from $30^{\circ} \mathrm{C}-60^{\circ} \mathrm{C}$ in Trilateral cycle.

\section{References}

[1]. Serrano J.R., Dolz V., Novella R., Garcia A. , 2011. HD Diesel engine equipped with a bottoming Rankine cycle as a Waste heat Recovery System. Applied Thermal Kevinj. Engineering 36 (2011), 279-287.

[2]. Wang X. D. Zhao L. Wang J.L, Zhang W. Z. , Zhao X .Z., W. Wu. 2009. Performance evaluation of low-temperature Solar Rankine cycle system utilizing R245fa. Solar Energy84 (2010), 353-364.

[3]. DiGenova Kevinj. Botros Barbara B, Brisson J.G., 2012. Method For customizing on organic Rankine cycle to a complex heat source for efficient energy conversion, demonstrated on Fischer Tropsh Pant. Applied Energy 102 (2013) 746-754.

[4]. Wang Dongxiang, Ling Xiang, Peng Hao. 2012. Performance Analysis of double organic Rankine cycle for discontinuous low temperature Waste heat Recovery. Applied Thermal Engineering 48 (2012) 63-71.

[5]. Larjola j., 1994. Electricity from industrial waste heat using high-speed organic Rankine cycle. International journal of Production Economics 41 (1995) 227-235.

[6]. Li jing, Pei Gang, Li YunhuLI, Ji jie.,2012. Evaluation of External heat loss from small-scale expander used in organic Rankine cycle. Applied Thermal Engineering 31 (2011) 26942701

[7]. Quilin S., Orosz M., Hemond H., Lemort V.,2012. Performance and design optimization of Low-cost solar organic Rankine cycle for remote Power generation. Solar Energy 85 (2011)955-966.85

[8]. Heberle Florian, Bruggemann Dieter., 2010. Exergy based fluid selection for geothermal organic Rankine cycle for combined heat and power generation. Applied Thermal Engineering 30 (2010).

[9]. Borsukiewiz-Gozdur Alesksandra .,2012. Pumping work in the organic Rankine .

[10]. Yamada Noboru, Mohamad Md Nor Anuar,Trinh Trung Kien .,2011. study on Thermal Efficiency of low to medium organic Rankine cycle using HFO-1234yf.Renewable Energy 41 (2012)368-375.cycle.Applied Thermal Engineering 51 (2013) $781-786$.

\begin{tabular}{ll} 
Nomenclature & \\
\hline HFO & Hydro-fluro -Olefin \\
HFC & Hydro-fluro-carbon \\
EES & Engineering equation solver \\
Ed & Exergy destruction $(\mathrm{kw})$ \\
$\mathrm{H}$ & Efficiency $(\%)$ \\
$\mathrm{T}$ & Temperature $\left({ }^{\circ} \mathrm{C}\right)$ \\
Subscripts & \\
Cond & condenser \\
Exp & expander \\
Pump & pump \\
Evap & evaporator \\
Ex & exergetic \\
In & inlet to expander \\
1 & Pump inlet state \\
2 & Pump exit state \\
3 & Expander inlet state \\
4 & Expander exit state \\
Greek letters $\eta$ & (efficiency) \\
\hline
\end{tabular}

